\title{
Models for assessing local-scale co-abundance of animal species while accounting for differential detectability and varied responses to the environment
}

\author{
Jedediah F. Brodie ${ }^{1,7}$ (D), Olga E. Helmy ${ }^{1}$, Jayasilan Mohd-Azlan ${ }^{2}$, Alys Granados $^{3}$, Henry Bernard ${ }^{4}$, Anthony J. Giordano ${ }^{5}$, and \\ Elise Zipkin 6 \\ ${ }^{1}$ Division of Biological Sciences \& Wildlife Biology Program, University of Montana, Missoula, MT 59802, USA \\ ${ }^{2}$ Department of Zoology, Faculty of Resource Science and Technology, Universiti Malaysia Sarawak, 94300 Kota Samarahan, Sarawak, \\ Malaysia \\ ${ }^{3}$ Department of Zoology, University of British Columbia, 2329 West Mall, Vancouver, BC V6T 1Z4, Canada \\ ${ }^{4}$ Institute for Tropical Biology and Conservation, Universiti Malaysia Sabah, 88999 Kota Kinabalu, Sabah, Malaysia \\ ${ }^{5}$ Field Conservation Program, SPECIES, P.O. Box 7403, Ventura, CA 93006, USA \\ ${ }^{6}$ Department of Integrative Biology, Michigan State University, East Lansing, MI 48824, USA
}

\begin{abstract}
We developed a new modeling framework to assess how the local abundance of one species influences the local abundance of a potential competitor while explicitly accounting for differential responses to environmental conditions. Our models also incorporate imperfect detection as well as abundance estimation error for both species. As a case study, we applied the model to four pairs of mammal species in Borneo, surveyed by extensive and spatially widespread camera trapping. We detected different responses to elevation gradients within civet, macaque, and muntjac deer species pairs. Muntjac and porcupine species varied in their response to terrain ruggedness, and the two muntjac responded different to river proximity. Bornean endemic species of civet and muntjac were more sensitive than their widespread counterparts to habitat disturbance (selective logging). Local abundance within several species pairs was positively correlated, but this is likely due to the species having similar responses to (unmodeled) environmental conditions or resources rather than representing facilitation. After accounting for environment and correcting for false absences in detection, negative correlations in local abundance appear rare in tropical mammals. Direct competition may be weak in these species, possibly because the 'ghost of competition past' or habitat filtering have already driven separation of the species in niche space. The analytical framework presented here could increase basic understanding of how ecological interactions shape patterns of abundance across the landscape for a range of taxa, and also provide a powerful tool for forecasting the impacts of global change.
\end{abstract}

Key words: Borneo; competition; co-occurrence; global change; Southeast Asia; species interactions.

DETERMINING WHICH SUBSETS OF REGIONAL SPECIES POOLS ASSEMBLE INTO LOCAL COMMUNITIES HAS BEEN A CENTRAL THEME THROUGHOUT THE HISTORY OF COMMUNity ECOlOgy (Darmon et al. 2012, HilleRisLambers et al. 2012, Cazelles et al. 2016). Certain species may consistently occur with or not occur with other species based on contemporary species interactions and environmental conditions (Morueta-Holme et al. 2016), a history of past interactions (Connell 1980, Silvertown 2004), or chance alone (Connor \& Simberloff 1979, Gotelli 2000).

The influence of climate and other environmental conditions on species distributions at large spatial scales is clear (Lomolino et al. 2006). But how conditions at smaller scales, and species interactions at any scale, influence distributions is poorly understood and still debated (Araujo \& Rozenfeld 2014, Cazelles et al. 2016). A critical question is whether, once environmental factors

Received 19 January 2017; revision accepted 21 July 2017.

${ }^{7}$ Corresponding author; e-mail: Jedediah.brodie@mso.umt.edu are accounted for, species interactions still influence distribution or abundance (Bullock et al. 2000, van Beest et al. 2014).

The reason that ecologists' understanding of how environment and interactions shape local-scale distributions remains poor is that, despite a vast literature on species co-occurrence, detecting such patterns can be difficult (Mod et al. 2016, MoruetaHolme et al. 2016). The gold standard is to experimentally remove one species and test for changes in the abundance of others (e.g., Munger \& Brown 1981, Segre et al. 2014). This is exceedingly difficult (and potentially unethical) for many animals, particularly species living at low densities in complex habitats. Co-occurrence has also been assessed through observational occurrence data, embodied in the search for 'checkerboard' distribution patterns and the debate over whether such patterns are driven by species interactions (Diamond 1975, Connor \& Simberloff 1979). Such datasets often consist of species presence $\times$ site matrices (Meyer \& Kalko 2008, Gotelli \& Ulrich 2010, Ulrich \& Gotelli 2013), and their analysis catalyzed the growth of statistical null models (Gotelli 2000, Ulrich \& Gotelli 